\title{
Santos, José Antonio. Los olvidados del nacionalsocialismo. Repensar la memoria, CEPC, Madrid, 2014, pp. 205.
}

\author{
Vicente Bellver Capella \\ Departamento de Filosofía del Derecho, Moral y Política \\ Universitat de València
}

Fecha de recepción: 07/01/2016 I De publicación: 22/06/2016

La monografía que publica José Antonio Santos resulta tan ambiciosa como arriesgada. A primera vista podría pensarse que se trata de un estudio sobre las bases culturales y legales de las prácticas eugenésicas durante el régimen nazi. Pero en cuanto uno ve el índice y comienza la lectura del texto descubre que el proyecto tiene un alcance mucho mayor. Por un lado, el autor bucea en las raíces históricas y filosóficas del movimiento eugenésico, que si bien alcanzó su clímax en la Alemania del nazismo, se manifestó también en las democracias más avanzadas en el primer tercio del siglo XX. Por otro, sigue el rastro de esa ideología hasta el tiempo presente y sus interesantes mutaciones en cuanto al lenguaje y los argumentos empleados para su justificación actual. Por si fuera poco, todo el libro está transido por una reflexión sobre la necesidad de la memoria para construir sociedades justas en el futuro y sobre el modo en que debe llevarse a cabo ese ejercicio de memoria.
La reflexión sobre el papel de la memoria para que se haga justicia en una sociedad suele activar el registro más emocional del lector: porque supone hablar de víctimas, y del papel que las generaciones presentes tienen con respecto a lo que hicieron sus ancestros.

La eugenesia tampoco es un asunto pacífico. Tras la $2^{\mathrm{a}}$ Guerra Mundial fue universalmente repudiada (al menos de forma oficial), pero no hubo una voluntad firme de conocer lo que realmente se había lleva a cabo. Tuvieron que pasar décadas para que los países en los que se habían perpetrado atrocidades al amparo de la higiene racial, decidieran mirar hacia atrás en busca de la memoria y la justicia. Pero para entonces estaba emergiendo un nuevo movimiento favorable a la eugenesia. Sus precursores reivindican el término porque están convencidos de que, si bien existe una eugenesia mala y perversa (la que se llevó en pos de una raza más sana), igualmente existe otra que es benéfica y compasiva: la que busca las "mejores" 
características genéticas para los propios hijos y evitar el sufrimiento de los que tienen una dotación genética especialmente deficiente.

Aproximarse al nazismo es también tarea difícil porque, a pesar de haber transcurrido ya 60 años de su completa liquidación, las heridas no están del todo restañadas. Si, para colmo y como hace José Antonio Santos, se decide ampliar el foco de atención desde la "Shoah" a la esterilización y eliminación de los discapacitados, entonces la posibilidad de salir airoso del intento resulta altamente improbable. Y, sin embargo, el autor lo logra. Quizá porque, en lugar de recurrir a la denuncia y a los juicios sumarísimos, ha optado por un camino más laborioso pero, a la larga, mucho más eficaz: indagar en las fuentes originales, presentarlas con rigor y dejar que el lector extraiga sus propias consecuencias. En la Introducción declara cuál ha sido su modo de proceder: "No se trata tanto de hacer un debate cruzado como de un análisis hermenéutico, desde un prisma amplio y abierto, que incluya una visión panorámica de determinada historia del pensamiento jurídico-filosófico alemán en el contexto de las llamadas 'vidas carentes de valor vital"” (p. 11).

Por todo ello, "Los olvidados del nacionalsocialismo" constituye una valiosa aportación para el público hispanohablante. Es cierto que algunos autores españoles han tratado desde una perspectiva jurídico-crítica el nazismo y las leyes dirigidas a los "asociales". Destacan particularmente las contribuciones del penalista Francisco Muñoz Conde y del iusfilósofo Javier Blázquez. Pero no existía todavía un estudio que enmarcara filosóficamente aquellas atrocidades ni reflexionara sobre las consecuencias de la ideología eugenésica para el presente. Como dice el propio autor, los enfermos físicos, psíquicos y discapacitados son "las víctimas olvidadas de la persecución nazi” (p. 14) puesto que corrieron una suerte pareja en muchos casos a la de los judíos $\mathrm{y}$, sin embargo, no han recibido la correspondiente atención. Este libro cubre esa importante laguna que existía en la literatura científica publicada en castellano.

Otra de las razones por la que el libro de José Antonio Santos culmina exitosamente el ambicioso objetivo que pretendía está en el rigor con el que ha trabajado las fuentes originales. No solo maneja las principales contribuciones publicadas sobre este tema en Alemania y en Estados Unidos (que apenas han sido traducidas al castellano) sino que ha accedido a muchos documentos originales de los años veinte y treinta del pasado siglo, que constituyen el armazón teórico de las leyes pro eugenesia y pro eutanasia que se fueron aprobando y aplicando en tantos países y, de forma muy destacada, en Alemania. 
El libro se desarrolla de acuerdo con una estructura histórica que resulta idónea para aproximarse al fenómeno de la eugenesia y la eutanasia en el nazismo a partir de sus raíces filosóficas y culturales.

El primer capítulo "Antecedentes de unos ídolos de barro" abraza el largo periodo comprendido desde Platón, primer autor en el que aparecen propuestas eugenésicas, hasta la Gran Guerra y la República de Weimar de los años veinte del pasado siglo. El profesor Santos identifica tres elementos que contribuirán decisivamente a fraguar las políticas eugenésicas anteriores a la $2^{\mathrm{a}}$ Guerra Mundial: la exaltación de los conceptos de "pueblo" y "nación" que lleva a cabo el Romanticismo; la alarma generada por el rápido crecimiento de la población en el siglo XIX y los efectos perniciosos que pueda traer consigo; y la teoría de la selección natural como causa de la evolución de las especies, elaborada por Darwin. Esta teoría científica dará pie para sustentar el darwinismo social, una de las ideologías más inhumanas que ha concebido el ser humano, que pretendía legitimar las políticas de selección de los individuos y de las razas, en función de su aptitud para la vida.

Como bien dice José Antonio Santos, para entender la irrupción de la ideología eugenésica en Alemania durante el nazismo resulta del todo insuficiente la Reductio ad Hitlerium; ni siquiera basta con añadir el paulatino declive jurídicomoral y económico acaecido en Alemania durante la República de Weimar. Es necesario apuntar a las bases filosófico-jurídicas sobre las que se levantará el robusto Derecho penal que algunos de los mejores penalistas del momento construyeron y que los jerarcas del nazismo supieron emplear tan eficazmente "pro domo sua". Este análisis es el núcleo del capítulo $2^{\circ}$, que lleva el elocuente título de "La República de Weimar como telón de fondo". Una atención especial presta el autor a la obra "Autorización para exterminar la vida sin valor vital", escrita por uno de los grandes maestros del Derecho penal del siglo XX, Karl Binding, y por el catedrático de Psiquiatría y persona de amplios intereses humanísticos, Alfred Hoche. Son dos autores que representan lo mejor del mundo académico en el país probablemente más culto del mundo y con una de las democracias más avanzadas del momento. Uno no puede dejar de preguntarse cómo unos individuos con tal nivel de ilustración pudieron alumbrar una obra como esa. Como bien sabemos, no fueron la excepción: entre los intelectuales del mundo desarrollado a principios del siglo XX, hubo un amplio respaldo a las tesis eugenésicas.

La pregunta a la que da respuesta la obra de Binding y Hoche es: “¿Existen vidas humanas que han sufrido tal menoscabo de su carácter de bien jurídico, que su continuidad ha perdido todo 
valor tanto para los titulares de esas vidas como para la sociedad?". La respuesta es obviamente "sí" y la consecuencia es la autorización para acabar con esas vidas. Se trata, como dice el propio Binding, de liberar de manera oficial a esas pobres personas de ellas mismas. La moral superior a la que apela el penalista no solo permite acabar con esas vidas sino que exige la intervención "oficial" del Estado para que todo se haga con las debidas garantías y para que no se deje de hacer lo que debe hacerse. Resulta sumamente interesante el análisis llevado a cabo por José Antonio Santos acerca de la recepción de esta obra a partir de las fuentes doctrinales del momento. Frente a la posición comúnmente admitida de que las propuestas de Binding $\mathrm{y}$ Hoche fueron mayoritariamente desechadas, el autor nos muestra una realidad mucho más compleja.

El capítulo $3^{\circ}$, titulado "Lenguaje y Derecho en el Nacionalsocialismo", trata de las leyes eugenésicas aprobadas y aplicadas en Alemania durante el nazismo. La lectura de esas informaciones resulta estremecedora no solo por el alcance de las atrocidades en cuanto a número y variedad, sino por la sólida fundamentación normativa con la que fueron llevadas a cabo. Por ello, resultan especialmente interesantes para el filósofo del Derecho las primeras páginas de este capítulo, en las que el prof. Santos analiza las bases teóricas en las que se apoyó Hitler para transformar una democracia en un régimen totalitario y construir el ordenamiento jurídico del nacionalsocialismo. Para hacer ese análisis el autor recurre a fuentes originarias pero también se apoya en Legaz Lacambra, quien ya en 1934 escribió un trabajo sobre la Filosofía del Derecho del Nacionalsocialismo. Como es bien sabido, uno de los principales artífices de esa doctrina fue Carl Schmitt, uno de los grandes filósofos de la política del siglo XX. Aunque nunca acabó de ganarse la confianza de Hitler (y, en consecuencia, no ocupó puestos destacados en el régimen), su contribución fue decisiva para dar cobertura legal a la absoluta sinrazón.

Tras la caída del nazismo al término de la $2^{\mathrm{a}}$ Guerra Mundial el pueblo alemán tuvo que afrontar y asimilar su reciente pasado. Los judíos se preocuparon de que la memoria del Holocausto ni se diluyera ni se escondiera. Sin embargo, el proceso de eliminación de las vidas carentes de valor vital solo fue tomado en consideración mucho más tarde y con no pocas dificultades. El capítulo $4^{\mathrm{o}}$ "Recordar el pasado y repensar la postguerra" se centra en la evolución de esa memoria que comenzó siendo olvido y que solo ha ido transformándose en justicia reparadora con mucho tesón, venciendo la resistencia a contemplar sin tapujos ese aspecto del pasado reciente. José Antonio Santos se centra en uno de los procesos judiciales de Nuremberg: el que se llevó a cabo contra los principales responsables 
médicos del nazismo acusados de crímenes contra la humanidad (1946), en la medida en que tuvieron una especial responsabilidad en la aplicación de medidas eugenésicas, eutanásicas y de experimentación con sujetos sin su consentimiento. Pero más allá de los episodios concretos que jalonan la aplicación de la justicia tras el nazismo, el autor relata la traumática asunción de la memoria por parte de la sociedad alemana y reflexiona sobre las exigencias con que debe llevarse a cabo para que no se construya injusticia sobre injusticia.

El libro concluye con el capítulo $5^{\circ}$, "Los tiempos del ayer", en el que José Antonio Santos quiere poner de manifiesto que la eugenesia y la eutanasia no son reliquias del pasado sino "un problema fundamental de la modernidad tanto en lo referente a su relativismo axiológico como a su cambio de valores, basados en el estándar de las sociedades industrializadas en las que prima lo útil y lo aprovechable" (p. 159). Para ello, no tiene problema en afrontar algunos de los debates bioéticos más controvertidos del momento: el relativo a la eutanasia precoz y al aborto postnatal, como prácticas de eugenesia negativa, y el del mejoramiento humano y el posthumanismo, como expresión contemporánea de la eugenesia positiva.

Como decía al principio, el libro de José Antonio Santos resulta ambicioso y, por ello, arriesgado. Pero tras su lectura uno se queda con la impresión de que ha culminado la empresa con éxito, ofreciendo una reflexión sobre un pasado todavía reciente que nos procura valiosas lecciones para el presente y el futuro inmediato. 